\title{
The contribution of body mass index to appraisal delay in colorectal cancer diagnosis: a structural equation modelling study
}

\author{
Karen E Dyer ${ }^{\star 1,2}$, Levent Dumenci ${ }^{1,3}$, Laura A Siminoff ${ }^{1,4}$, Maria D Thomson ${ }^{1}$ and Jennifer Elston Lafata ${ }^{1,5}$ \\ ${ }^{1}$ Virginia Commonwealth University, School of Medicine, Department of Health Behavior and Policy, P.O. Box 980149, Richmond, \\ VA 23298, USA
}

Background: Appraisal delay (AD) refers to the time interval between onset of symptoms and the date a patient first seeks healthcare. Because studies have shown that individuals who are overweight or obese may delay or avoid seeking healthcare due to stigma, this study aims to investigate the role that weight plays in $A D$ among symptomatic individuals subsequently diagnosed with colorectal cancer (CRC).

Methods: Structural equation modelling tested the relationship between AD, body mass index (BMI), financial barriers, cognitive barriers, and reported symptoms among 179 newly diagnosed CRC patients in two U.S. healthcare systems.

Results: $\mathrm{BMI}$ was directly and significantly related to $\mathrm{AD}(\beta=0.10 ; P=0.044)$ and to cognitive barriers $(\beta=0.24 ; P=0.005)$. Cognitive barriers were direct and significant predictors of increased $\operatorname{AD}(\beta=0.32 ; P=0.000)$. Symptom experience and financial barriers were mediated through cognitive barriers.

Conclusions: Model results support the hypothesis that increased BMI is significantly and directly associated with increased AD and key cognitive barriers relevant to care-seeking behaviour.

Delays in colorectal cancer (CRC) diagnosis pose a continuing challenge to timely treatment efforts worldwide, and may result from a combination of patient, practitioner, and health system factors (Mitchell et al, 2008; Butler et al, 2013). Obesity is a known CRC risk factor (Renehan et al, 2008; Norat et al, 2010); however, obesity-related stigma is pervasive (Puhl and Heuer, 2010), and both obesity and its related stigma have been linked to healthcareseeking delays and avoidance (Merrill and Grassley, 2008; Mold and Forbes, 2013). For example, a medical chart review study examining receipt of CRC screening found that obese patients had $25 \%$ decreased odds of having been screened compared to nonobese patients (Ferrante et al, 2006).

Because of the linkages among obesity, CRC risk and healthcare-seeking behaviour, we became interested in the potential role of body mass index (BMI) in CRC diagnostic delays. Delays can be characterised according to intervals between specific time-points: dates of first symptom, first presentation, referral, and diagnosis (Weller et al, 2012). Here we consider delays occurring in

\footnotetext{
*Correspondence: Dr KE Dyer; E-mail: karen.dyer@va.gov

2Present address: VA HSR\&D Center for the Study of Healthcare Innovation, Implementation \& Policy (CSHIIP), VA Greater Los Angeles Healthcare System, 11301 Wilshire Boulevard (111G), Los Angeles, CA 90073, USA.

${ }^{3}$ Present address: Temple University, College of Public Health, Department of Epidemiology and Biostatistics, 1101 W. Montgomery Avenue, 3rd Floor, Philadelphia, PA 19122, USA.

${ }^{4}$ Present address: Temple University, College of Public Health, Department of Social and Behavioral Sciences, 1101 W. Montgomery Avenue, 3rd Floor, Philadelphia, PA 19122, USA.

${ }^{5}$ Present address: University of North Carolina at Chapel Hill, UNC Lineberger Comprehensive Cancer Center and UNC Eshelman School of Pharmacy, Division of Pharmaceutical Outcomes and Policy, Kerr Hall, CB\# 7573, Chapel Hill, NC 27599, USA.
}

Received 1 November 2016; revised 29 March 2017; accepted 10 April 2017; published online 2 May 2017

(C) 2017 Cancer Research UK. All rights reserved 0007-0920/17 
the first interval, often termed appraisal delay (AD) (Mitchell et al, 2008; Simon et al, 2010). We have shown in a previous study that $\mathrm{AD}$ is strongly associated with four avoidant coping behaviours, or 'cognitive barriers,' among symptomatic CRC patients; these behaviours mediate the impact of financial barriers and reported symptoms on AD (Siminoff et al, 2011; Siminoff et al, 2014). However, it is not well-understood which patients may face these barriers. Because of previously-identified associations between obesity and healthcare avoidance, we tested the role that increased $\mathrm{BMI}$ may play in $\mathrm{AD}$ in the same sample.

\section{MATERIALS AND METHODS}

This was a cross-sectional, mixed-methods study designed to test whether or not BMI contributes to increases in $\mathrm{AD}$ among symptomatic patients subsequently diagnosed with CRC. Patients were recruited from academic and community oncology settings in two U.S. states, had been diagnosed with CRC stages I-IV within the previous six months, and were experiencing symptoms before initial healthcare consultation. Data collection methods for the larger study are detailed elsewhere, and included medical chart reviews and two-hour semi-structured interviews with 252 newly diagnosed CRC patients (Siminoff et al, 2011, 2014). A second chart review was conducted at a later date to extract documented height/weight for BMI calculation. The study was approved by relevant ethics boards and all participants provided informed consent.

The primary outcome variable was $\mathrm{AD}$, operationalized as the time elapsed between patient-reported symptom onset and medical record-verified date of first provider consultation. $\mathrm{AD}$ was calculated as a continuous measure in months and log-transformed for analysis.

BMI was calculated from medical record-documented height/ weight and used as both a continuous measure and ordinal measure. The variable 'financial barriers' represented the presence/ absence of patient-reported financial difficulties to seeking healthcare. 'Cognitive barriers' was a latent variable representing the presence/absence of four avoidant coping behaviours: patients' fear of tests, embarrassment seeking care, belief that patient is too young to have cancer, and belief that symptoms are not serious. 'Reported symptoms' represented the number of cardinal CRC symptoms participants experienced before seeking healthcare (range $=0-10)$. Socio-demographic variables were derived from a structured questionnaire.

Statistical analysis. Chi-square tests and independent samples $t$-tests were used to identify differences in the above variables

Table 1. Sample characteristics

\begin{tabular}{|c|c|c|c|c|c|c|}
\hline Variable & $\begin{array}{l}\text { Full sample } \\
(N=252)\end{array}$ & \multicolumn{2}{|c|}{ BMI Data } & \multicolumn{3}{|c|}{ BMI category } \\
\hline \multicolumn{7}{|l|}{ Age } \\
\hline$<50$ years & $25.4 \%(64)$ & $25.1 \%(45)$ & $26.0 \%(19)$ & $20.4 \%(11)$ & $19.0 \%(11)$ & $34.3 \%(23)$ \\
\hline $50-75$ years & $64.3 \%(162)$ & $64.8 \%(116)$ & $63.0 \%(46)$ & $63.0 \%(34)$ & $74.1 \%(43)$ & $58.2 \%(39)$ \\
\hline Caucasian & $52.8 \%(133)$ & $54.7 \%(98)$ & $47.9 \%(35)$ & $64.8 \%(35)$ & $48.3 \%(28)$ & $52.2 \%(35)$ \\
\hline African American & $44.0 \%(111)$ & $41.9 \%(75)$ & $49.3 \%(36)$ & $27.8 \%(15)$ & $50.0 \%(29)$ & $46.3 \%(31)$ \\
\hline Other & $3.2 \%(8)$ & $3.4 \%(6)$ & $2.7 \%(2)$ & $7.4 \%(4)$ & $1.7 \%(1)$ & $1.5 \%(1)$ \\
\hline \multicolumn{7}{|l|}{ Gender } \\
\hline Male & $52.4 \%(132)$ & $50.8 \%(91)$ & $56.2 \%(41)$ & $44.4 \%(24)$ & $51.7 \%(30)$ & $55.2 \%(37)$ \\
\hline Female & $47.6 \%(120)$ & $49.2 \%(88)$ & $43.8 \%(32)$ & $55.6 \%(30)$ & $48.3 \%(28)$ & $44.8 \%(30)$ \\
\hline$\$ 50000-74000$ & $10.3 \%(26)$ & $11.2 \%(20)$ & $8.2 \%(6)$ & $3.7 \%(2)$ & $10.3 \%(6)$ & $17.9 \%(12)$ \\
\hline$\$ 75000-100000$ & $13.1 \%(33)$ & $14.5 \%(26)$ & $9.6 \%(7)$ & $20.4 \%(11)$ & $12.1 \%(7)$ & $11.9 \%(8)$ \\
\hline$>\$ 100000$ & $11.9 \%(30)$ & $14.0 \%(25)$ & $6.8 \%(5)$ & $9.3 \%(5)$ & $22.4 \%(13)$ & $10.4 \%(7)$ \\
\hline Don't know & $4.8 \%(12)$ & $2.8 \%(5)$ & $9.6 \%(7)$ & $3.7 \%(2)$ & $3.4 \%(1)$ & $2.8 \%(1)$ \\
\hline \multicolumn{7}{|l|}{ Marital status ${ }^{b}$} \\
\hline Married/Partnered & $52.4 \%(132)$ & $52.5 \%(94)$ & $52.1 \%(38)$ & $38.9 \%(21)$ & $46.6 \%(27)$ & $68.7 \%(46)$ \\
\hline Not married/Partnered & $47.6 \%(120)$ & $47.5 \%(85)$ & $47.9 \%(35)$ & $61.1 \%(33)$ & $53.4 \%(31)$ & $31.3 \%(21)$ \\
\hline \multicolumn{7}{|l|}{ Education } \\
\hline HS degree or less & $47.6 \%(120)$ & $45.8 \%(82)$ & $52.1 \%(38)$ & $50.0 \%(27)$ & $43.1 \%(25)$ & $44.8 \%(30)$ \\
\hline Some college or higher & $52.0 \%(131)$ & $54.2 \%(97)$ & $46.6 \%(34)$ & $50.0 \%(27)$ & $56.9 \%(33)$ & $55.2 \%(37)$ \\
\hline Missing & $0.4 \%(1)$ & $0.0 \%(0)$ & $1.4 \%(1)$ & $0.0 \%(0)$ & $0.0 \%(0)$ & $0.0 \%(0)$ \\
\hline \multicolumn{7}{|l|}{ Occupation } \\
\hline
\end{tabular}


Table 2. Financial barriers, cognitive barriers, and symptoms

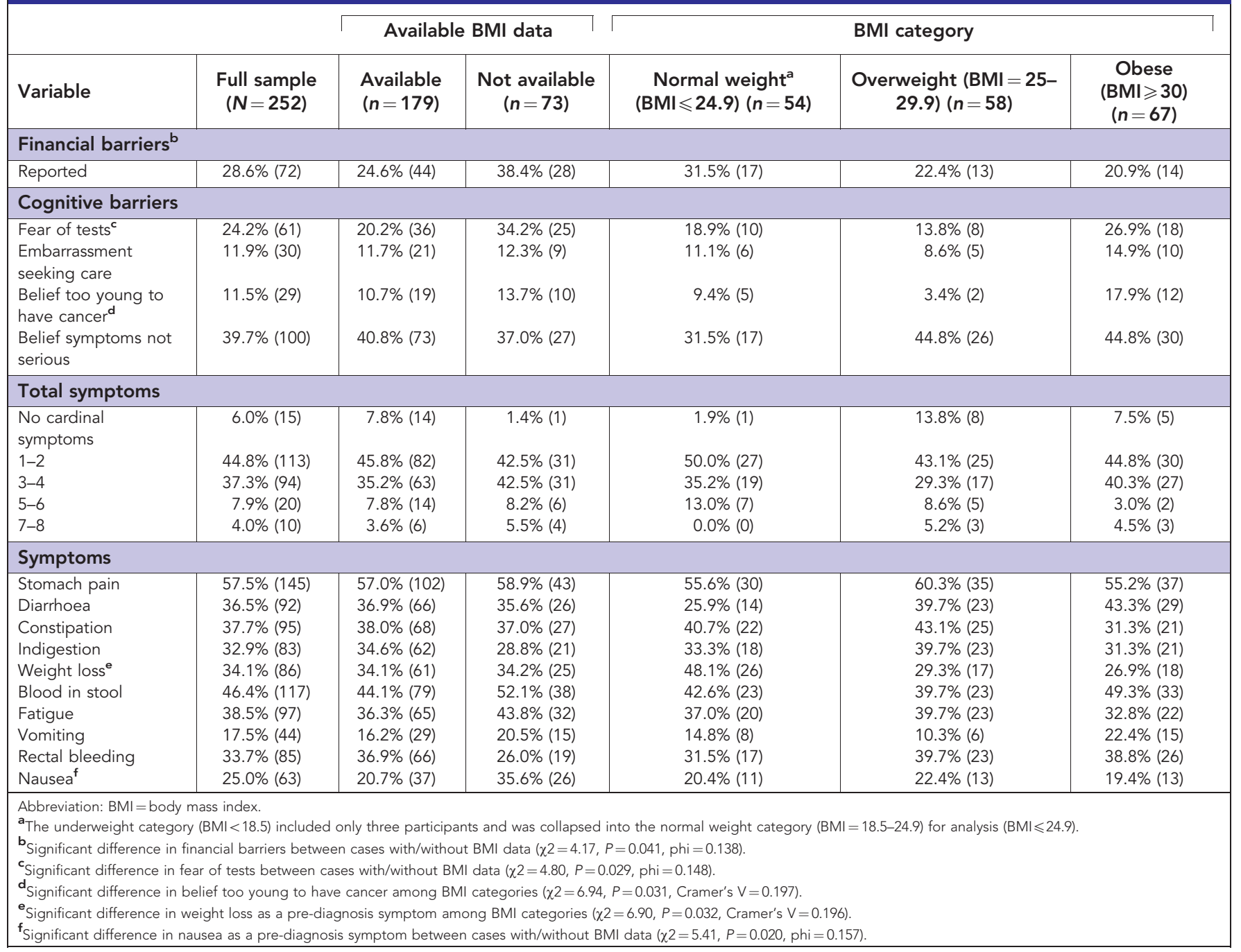

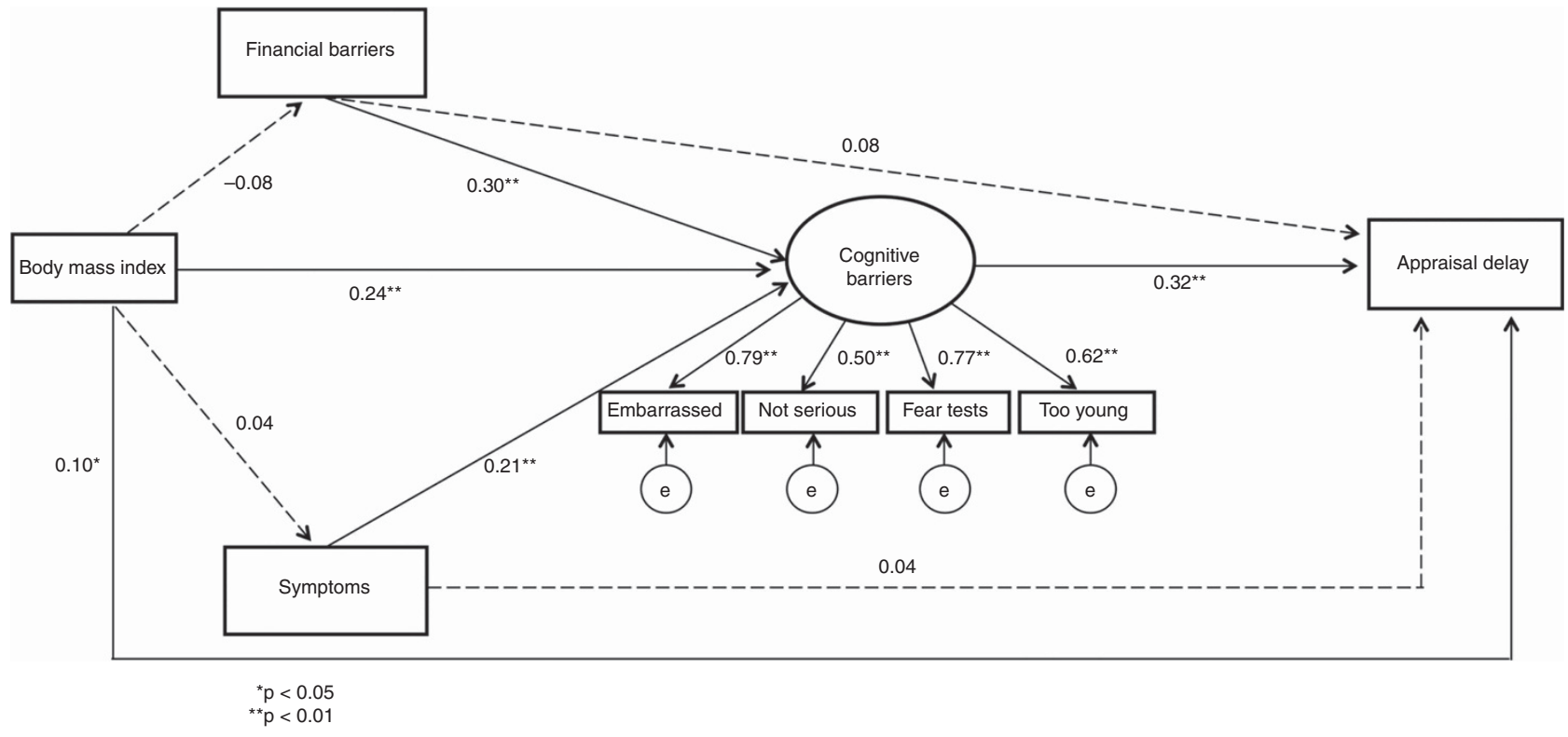

Figure 1. Mediation model with standardised parameter estimates. Final model of factors contributing to AD (outcome variable), including BMI, financial barriers, reported symptoms, and cognitive barriers, with standardised parameter estimates $(\beta)(n=179)$. 
between cases for whom BMI could and could not be calculated and among BMI categories. ANOVAs were used to identify differences in $\mathrm{AD}$ length by BMI category.

Using results from Siminoff and colleagues as a guide (Siminoff et al, 2014), we developed a conceptual framework hypothesising an association between $\mathrm{AD}$ and $\mathrm{BMI}$ (continuous measure), financial barriers, reported symptoms, and cognitive barriers (Supplementary Figure 1). Because the prior analysis illustrated the importance of considering the direct and indirect effects of predictor variables, and because the cognitive barriers construct available was a latent (or unobserved) variable, we used structural equation modelling to test these relationships. Structural equation modelling represents a flexible approach to estimating several equations simultaneously, with the same variable serving as predictor in one equation and criterion in another. It allows for latent variable estimation simultaneously with other models of interest (Nachtigall et al, 2003). Full information maximum likelihood (FIML) estimation was used to fit the model to handle missing data. Mplus (v7.4) was used for model estimation.

\section{RESULTS}

The mean age of the sample was 57.9 years (s.d. \pm 12.2, median $=57.0$ ). See Table 1 for sociodemographic characteristics and Table 2 for information on financial barriers, cognitive barriers, and total and specific symptoms reported. Financial barriers were reported by $28.6 \%(n=72)$ of the total sample, cognitive barriers were expressed by $52.0 \% \quad(n=131)$, and mean number of symptoms reported was 2.6 (s.d. \pm 1.7 , range $=0-8)$.

A total of 179 patients (71.0\%) out of 252 had sufficient medical record documentation to enable BMI calculation. Few differences between the two groups were found, although cases with BMI information were less likely to report financial barriers $(24.6 \% v s$ $38.4 \%, P=0.041)$, express a fear of tests $(20.2 \%$ vs $34.2 \%$, $P=0.029)$, or experience nausea pre-diagnosis $(20.7 \%$ vs $35.6 \%$, $P=0.020)$. The sample reflected the U.S. population's age-adjusted weight distribution (CDC, 2015): $30.2 \%(n=54)$ were underweight/normal weight, $32.4 \%(n=58)$ were overweight, and $37.4 \%$ $(n=67)$ were obese. Significant differences were found among BMI groups in marital status $(38.9 \%, 46.6 \%, 68.7 \%$ married, $P=0.003)$, belief that patient is too young to have cancer $(9.4 \%$, $3.4 \%, 17.9 \%, P=0.031$ ), and pre-diagnosis weight loss $(48.1 \%$, $29.3 \%, 26.9 \%, P=0.032$ ). Mean BMI was 29.2 (s.d. \pm 7.2 , range $=13.0-60.8$ ). Mean $\mathrm{AD}$ was 4.8 months (s.d. \pm 7.0 , range $=0.0-57.2$ ) for all participants, with no significant differences among groups.

The mediation model with standardised parameter estimates is shown in Figure 1. Though prior analyses tested the demographic variables and did not find the covariate effects to be significant, they were adjusted for in this model and were again not significant. The unadjusted mediation model resulted in good fit to the data $\left(x^{2}=15.45 ; \mathrm{df}=14 ; P=0.349 ; \mathrm{CFI}=0.99 ; \mathrm{TLI}=0.98 ; \quad \mathrm{RMSEA}\right.$ $(90 \% \mathrm{CI})=0.02(0.00-0.07))$. The direct effect of BMI on AD was significant $(\beta=0.10 ; P=0.044)$. The relationship between BMI and $\mathrm{AD}$ was also mediated through the cognitive barriers variable $(\beta=0.24 ; P=0.005)$, which itself had a significant direct effect on $\operatorname{AD}(\beta=0.32 ; P=0.000)$. The standardised factor loadings for the latent variable supported their use (i.e., they ranged from 0.50 to 0.79 and were all significant $(P<0.01))$. As in the initial model, reported symptoms $(\beta=0.04 ; P=0.470)$ and financial barriers $(\beta=0.08 ; P=0.215)$ did not have significant direct effects on $\mathrm{AD}$, and were not significantly associated with $\mathrm{BMI}(\beta=0.04 ; P=0.639$ and $\beta=-0.08 ; P=0.246$, respectively). Instead, the effects of symptoms $(\beta=0.21 ; P=0.010)$ and financial barriers $(\beta=0.30$;
$P=0.000)$ on $\mathrm{AD}$ were mediated through the set of cognitive barriers, indicating that patients' subjective experiences of their symptoms and financial situation were not independently related to healthcare-seeking behaviours but instead were governed by their beliefs and emotions surrounding cancer and testing. The variables included in this model explained $15.3 \%$ of the variability in $\mathrm{AD}$.

\section{DISCUSSION}

This study sought to determine the contribution of BMI to $\mathrm{AD}$ among symptomatic CRC patients. Model results supported the hypothesis that increased BMI is significantly and directly associated with increased $\mathrm{AD}$, as well as key cognitive barriers involved in care-seeking behaviour. Cognitive barriers were direct and significant predictors of increased $\mathrm{AD}$, and mediated the impact of both symptom experience and financial barriers.

Obesity-related stigma has been shown to play a role in healthcare-seeking delays and avoidance (Mold and Forbes, 2013). While we did not directly measure stigma, two cognitive barriers tested here are related: embarrassment seeking care and fear of tests (Simon et al, 2010; Forbes et al, 2014; May et al, 2016). These barriers may be exacerbated for overweight patients given research underscoring the negative impacts of obesity stigma, such as demeaning interactions with providers, embarrassment being weighed, and a need for differently-sized equipment and gowns (Amy et al, 2006; Merrill and Grassley, 2008). They may also interact with the non-specificity of many CRC symptoms, such as gastrointestinal distress. Specifically, individuals with high BMI can experience a greater number of co-morbidities or physical discomfort, which may heighten appraisal difficulties.

Findings should be interpreted with limitations in mind. First, a subset of medical records lacked sufficient height/weight documentation for BMI calculation; ideally, weight would be measured anthropometrically at symptom onset. The risk of selectivity bias may limit generalisability, although minimal differences were found between participants with/without BMI data. Our approach to handling missing data using FIML estimation was conservative, and findings remain robust. Second, it is possible that retrospective self-report resulted in recall bias, although we used accepted recall stimulation techniques (Barsky, 2002) and studies have demonstrated the reliability of CRC symptom self-report (Adelstein et al, 2008). Finally, this study may not be generalisable to non-U.S. healthcare contexts.

While this study cannot determine causality, it provides a basis for future prospective analyses focused on weight and healthcareseeking delays. Findings highlight the need to consider the complex interplay between individual perceptions, social norms and health system factors (such as the availability of weightaccommodating equipment) that is likely contributing to the observed relationship between weight and increased AD. Although we studied this relationship among newly diagnosed patients, a similar relationship is likely to exist across the cancer care continuum, from screening to treatment, surveillance and even end-of-life care.

\section{ACKNOWLEDGEMENTS}

KED and MT were supported by NCI Grant No. R25-CA09342307 (Training Program in Behavioral and Health Services Cancer Control Research). LD and LAS were supported by NCI Grant No. R01-CA124607 (Appraisal and Diagnostic Delay in Colon Cancer). 


\section{CONFLICT OF INTEREST}

The authors declare no conflict of interest.

\section{REFERENCES}

Adelstein BA, Irwig L, Macaskill P, Katelaris PH, Jones DB, Bokey L (2008) A self-administered reliable questionnaire to assess lower bowel symptoms. BMC Gastroenterol 8: 8.

Amy NK, Aalborg A, Lyons P, Keranen L (2006) Barriers to routine gynecological cancer screening for White and African-American obese women. Int J Obes (Lond) 30: 147-155.

Barsky AJ (2002) Forgetting, fabricating, and telescoping: the instability of the medical history. Arch Intern Med 162: 981-984.

Butler J, Foot C, Bomb M, Hiom S, Coleman M, Bryant H, Vedsted P, Hanson J, Richards M, ICBP Working Group (2013) The International Cancer Benchmarking Partnership: an international collaboration to inform cancer policy in Australia, Canada, Denmark, Norway, Sweden and the United Kingdom. Health Policy 112: 148-155.

Centers for Disease Control and Prevention (CDC) (2015) Normal weight, overweight, and obesity among adults aged 20 and over, by selected characteristics: United States, selected years 1988-1994 through 2011-2014 (NHANES National Health and Nutrition Examination Survey) [Online]. Available from https://www.cdc.gov/nchs/hus/ contents2015.htm\#058 (accessed on 28 March 2017).

Ferrante JM, Ohman-Strickland P, Hudson SV, Hahn KA, Scott JG, Crabtree BF (2006) Colorectal cancer screening among obese versus non-obese patients in primary care practices. Cancer Detect Prev 30: 459-465.

Forbes LJL, Warburton F, Richards MA, Ramirez AJ (2014) Risk factors for delay in symptomatic presentation: a survey of cancer patients. Br J Cancer 111: $581-588$

May FP, Whitman CB, Varlyguina K, Bromley EG, Spiegel BM (2016) Addressing low colorectal cancer screening in African Americans: using focus groups to inform the development of effective interventions. J Cancer Educ 31: 567-574.

Merrill E, Grassley J (2008) Women's stories of their experiences as overweight patients. J Adv Nurs 64: 139-146.
Mitchell E, Macdonald S, Campbell NC, Weller D, Macleod U (2008) Influences on pre-hospital delay in the diagnosis of colorectal cancer: a systematic review. Br J Cancer 98: 60-70.

Mold F, Forbes A (2013) Patients' and professionals' experiences and perspectives of obesity in health-care settings: a synthesis of current research. Health Expect 16: 119-142.

Nachtigall C, Kroehne U, Funke F, Steyer R (2003) (Why) should we use SEM? Pros and cons of structural equation modeling. Method Psych Res Online 8: 1-22.

Norat T, Chan D, Lau R, Aune D, Vieira R (2010) The associations between food, nutrition, and physical activity and the risk of colorectal cancer. WCRF/AICR Systematic Literature Review Continuous Update Project Report. World Cancer Research Fund International/American Institute for Cancer Research: London, UK. Available from http://www.wcrf.org/sites/ default/files/SLR_colorectal_cancer_2010.pdf (accessed on 28 March 2017).

Puhl RM, Heuer CA (2010) Obesity stigma: important considerations for public health. Am J Public Health 100: 1019-1028.

Renehan AG, Tyson M, Egger M, Heller RF, Zwahlen M (2008) Body-mass index and incidence of cancer: a systematic review and meta-analysis of prospective observational studies. Lancet 371: 569-578.

Siminoff LA, Rogers HL, Thomson MD, Dumenci L, Harris-Haywood S (2011) Doctor, what's wrong with me? Factors that delay the diagnosis of colorectal cancer. Patient Educ Couns 84: 352-358.

Siminoff LA, Thomson MD, Dumenci L (2014) Factors associated with delayed patient appraisal of colorectal cancer symptoms. Psychooncology 23: 981-988.

Simon AE, Waller J, Robb K, Wardle J (2010) Patient delay in presentation of possible cancer symptoms: the contribution of knowledge and attitudes in a population sample from the United Kingdom. Cancer Epidemiol Biomarkers Prev 19: 2272-2277.

Weller D, Vedsted P, Rubin G, Walter FM, Emery J, Scott S, Campbell C, Andersen RS, Hamilton W, Olesen F, Rose P, Nafees S, Van Rijswijk E, Hiom S, Muth C, Beyer M, Neal RD (2012) The Aarhus Statement: improving design and reporting of studies on early cancer diagnosis. $\mathrm{Br} J$ Cancer 106: 1262-1267.

This work is published under the standard license to publish agreement. After 12 months the work will become freely available and the license terms will switch to a Creative Commons AttributionNonCommercial-Share Alike 4.0 Unported License.

Supplementary Information accompanies this paper on British Journal of Cancer website (http://www.nature.com/bjc) 